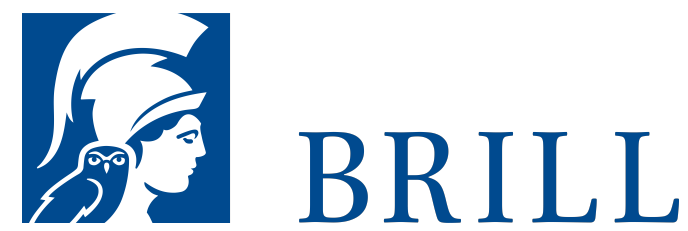

\title{
Die Logik der Zustimmung
}

Historische und systematische Perspektiven epistemischer Logik

\section{Author: Werner Stelzner}

In diesem Buch wird der Begriff der Zustimmung in seinen unterschiedlichen Ausprägungen in drei Teilen herausgearbeitet (Teil I: Zustimmung in der Philosophie der Neuzeit und in der traditionellen Logik, Teil II: Zustimmung in der modernen Philosophie, Teil III: Die logische Analyse der Zustimmung). Der neuzeitlichen Tradition in der Verwendung des Zustimmungsbegriffs folgend, erfolgt seine Analyse in Verbindung mit epistemischen und sprechakttheoretischen Begriffen wie Glaube und Überzeugung, Fürwahrhalten, Urteil, Akzeptation und Behauptung. Im Hauptteil des Buchs wird im Rahmen der Unterscheidung zwischen der Logik innerer Zustimmung und der Logik äußerer Zustimmung das Verhältnis von Zustimmung, Widerspruch und Folgerung sowie von Zustimmungsfolgerung und Relevanz dargestellt. Hier erfolgt die Behandlung der Zustimmung in formalisierten Sprachen, wodurch sich eine präzise und die logischen Konsequenzen klar umfassende Explikation des Zustimmungsbegriffs ergibt. Die Studie verfolgt das Ziel, Anwendungen der epistemischen Logik in der Philosophie des Geistes, der Erkenntnistheorie, der Argumentationstheorie und der künstlichen Intelligenz zu fördern.

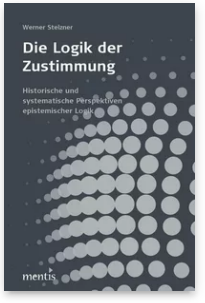

Pages: 542

Seiten

Language:

German

Subjects:

General,

Philosophy

Publisher: Brill | mentis

E-Book (PDF)

Released online:

o1 Jun 2013

ISBN: 978-3-

95743-953-6

List price

Paperback

Publication date:

o1 Jun 2013

ISBN: 978-3-

89785-803-9

List price 
For more information see brill.com

Order information: Order online at brill.com +44330 333 0049 | customerservices@brill.com Submission information: brill.com/authors

Titles published by Brill | Fink, Brill | mentis or Brill | Schöningh: +49(o)715413279216| brill@brocom.de 